DOI: 10.4274/jarem.galenos.2021.18291

J Acad Res Med 2021;11(2):199-205

\title{
Evaluation of the Appearance Characteristics of Suspicious Microcalcifications Detected by Ultrasonography
}

\author{
(1) Yasemin Kayadibi1, (1) Deniz Esin Tekcan Şanlı2, (1) Neşe Uçar3, (10) Emine Yıldırım4, (10) Ahmet Necati Şanlı5 \\ ${ }^{1}$ istanbul University-Cerrahpaşa, Cerrahpaşa Faculty of Medicine, Department of Radiology, İstanbul, Turkey \\ ${ }^{2}$ istanbul Rumeli University, Vocational School of Health Services, Department of Medical Imaging Techniques, İstanbul, Turkey \\ ${ }^{3}$ University of Health Sciences Turkey, Gaziosmanpaşa Training and Research Hospital, Clinic of Radiology, İstanbul, Turkey \\ ${ }^{4}$ University of Health Sciences Turkey, Gaziosmanpaşa Training and Research Hospital, Clinic of General Surgery, İstanbul, Turkey \\ ${ }^{5}$ İstanbul University-Cerrahpaşa, Cerrahpaşa Faculty of Medicine, Department of General Surgery, İstanbul, Turkey
}

Cite this article as: Kayadibi Y, Tekcan Şanlı DE, Uçar N, Yıldıım E, Şanlı AN. Evaluation of the Appearance Characteristics of Suspicious Microcalcifications Detected by Ultrasonography. J Acad Res Med 2021;11(2):199-205

\begin{abstract}
Objective: To investigate the imaging properties of mammographically suspicious microcalcifications (MC) that can be detected by ultrasonography (USG).

Methods: Cases with suspected MC in categories 4 and 5 according to the Breast Imaging-Reporting and Data System (BI-RADS) in screening mammography between June 2019 and January 2021 were included in the study. The patients were scanned with USG. USG guided core needle biopsy was performed for those whose MC area could be detected by USG and evaluated histopathologically. Mammographic features of MCs [morphological type (fine pleomorphic, amorphic, coarse heterogeneous, fine linear pleomorphic branching)], distribution (clustered, regional, segmental, diffuse, linear) and BI-RADS $(4 \mathrm{~A}, 4 \mathrm{~B}, 4 \mathrm{C}, 5)$ category was determined. Other findings accompanying $\mathrm{MC}$ areas on mammography and USG were recorded.

Results: The mean age of 43 patients included in the study was $45.27 \pm 8.58$ (30-84). $48.8 \%(n=21)$ of the calcifications were fine pleomorphic, $30 \%$ ( $n=13)$ amorphous, $16 \%(n=7)$ coarse heterogeneous, $4.6 \%(n=2)$ fine pleomorphic branching type. While $70 \%(n=30)$ of the patients had asymmetrical density accompanying MCs on mammography, parenchymal distortion was found in $12 \%(n=5)$; on USG, hypoechoic area was found in $58 \%$ ( $n=25$ ) of the patients, irregular ductal ectasia in 19\% $(n=8)$, parenchymal distortion in $9 \%(n=4)$, and $10 \%(n=4)$ microcyst cluster were accompanying pathologies. As a result of the histopathological evaluation, $42 \%$ of the patients had benign histopathology ( $n=18), 16 \%$ had ductal carcinoma in situ $(n=7)$, and $42 \%(n=18)$ had invasive ductal cancer.

Conclusion: In our study, the distinctive features of BI-RADS 4 and 5 MCs that can be followed by USG were evaluated. Although MCs that can be detected on USG are more likely to be malignant than benign ones, fine pleomorphic MC areas can be observed most frequently. Knowing the features of mammographic suspected MCs on USG will be helpful in daily radiology practice and biopsy planning.
\end{abstract}

Keywords: Microcalcification, mammography, ultrasonography, ultrasound guided biopsy

ORCID IDs of the authors: Y.K. 0000-0003-1590-5382; D.E.T.Ş. 0000-0002-6545-5757; N.U. 0000-0003-2233-4338; E.Y. 0000-0003-2733-402X; A.N.Ş. 0000-0002-1483-8176.

Sorumlu Yazar/Corresponding Author: Yasemin Kayadibi, E-mail: ysmnkayadibi@gmail.com
Geliş Tarihi/Received Date: 13.05.2021 Kabul Tarihi/Accepted Date: 21.06.2021

(C) Copyright 2021 by University of Health Sciences Turkey, Gaziosmanpaşa Training and Research Hospital. Available on-line at www.jarem.org 


\section{INTRODUCTION}

Mammography is the gold standard imaging method for detecting and characterizing microcalcifications (MC) (1). Ductal carcinoma in situ (DCIS) constitutes $25 \%$ of suspected MC on mammography $(2,3)$. $90 \%$ of DCIS cases are detected through mammography, which is classified as category 4 or 5 according to the Breast Imaging-Reporting and Data System (BI-RADS) and through mammograms recommended histopathological evaluation (4-7). Ultrasonography (USG) has an important role in the characterization of breast lesions detected by mammography (8). However, the diagnostic power of USG is limited in the detection of MCs that may not be accompanied by a mass, which may be a sign of malignancy $(9,10)$. The detection of MCs with USG becomes easier thanks to the new technological algorithms such as use of high-frequency probes, the development of artifact removal software, tissue harmonic and compound imaging and MicroPure imaging $(9,11,12)$. This situation has raised the question of whether USG guided biopsy can be applied in the histopathological diagnosis of MCs. Although stereotaxic biopsy is the most reliable method for sampling MCs, it has some disadvantages such as prolonged compression, radiation exposure and expensive equipment requirement. In addition, it is difficult to access the pathological area in cases where it is not available in all health centers, the breast volume is very small, and close to the chest wall or axilla $(5-7,13)$. Compared to stereotaxic biopsy, USG guided biopsy is a less painful, faster, more comfortable, cheaper, radiation-free, real-time method that allows manipulation $(6,12)$. The disadvantage of USG-guided biopsy is that it is difficult to detect MCs without a mass, and this rate varies between $24 \%$ and $93 \%$ according to publications in the literature $(9,11,12,14,15)$. Our aim in this study was to investigate the sonographic features of MCs that can be detected by USG, are not accompanied by a mammographic mass, and classified as category BI-RADS 4 or 5 .

\section{METHODS}

\section{Patient Group}

After the approval of the local hospital ethics committee (approval number 252 dated 14/04/2021), patients with BIRADS 4 or 5 microcalcifications were screened between 2019-2021. Patients whose non-mass microcalcifications could be observed under USG and who underwent USG-guided core needle biopsy were included in the study. Patients who had undergone previous breast surgery, treated for breast cancer, and were in the ongoing pregnancy or breastfeeding period were excluded from the study. In addition, a signed informed consent form was obtained from all patients.

\section{Imaging Method and Image Analysis}

Images of all patients were taken in standardized mediolateral oblique and craniocaudal positions with our hospital mammography device (Giotto Image MC, IMS, Italy). Mammography images of the patients were reviewed retrospectively from the hospital Picture Archiving and
Communication System (PACS). According to BI-RADS $5^{\text {th }}$ edition (2013), patients were evaluated for mammographic breast density (type A-B-C-D), type of MC (amorphous, fine pleomorphic, coarse heterogeneous, fine linear and fine pleomorphic branching), distribution pattern (clustered, regional, segmental, diffuse, linear) and the BI-RADS category $(4 A, 4 B, 4 C, 5)$ was determined (4). Other accompanying findings (asymmetrical density increase, parenchymal distortion) on mammography were recorded. Then, USG examination was performed on these patients. All sonographic examinations were performed with the Toshiba Aplio 500 machine (software version 6.0, Toshiba Medical Systems, Tokyo, Japan). First, routine breast USG was performed on both breasts. Then, the region containing the $\mathrm{MC}$ was tried to be localized according to the clock dial, its depth from the skin, its distance from the nipple, chest wall and intramammary lymph nodes. Sonographic findings (hypoechoic area, irregularly dilated ducts, microcyst cluster, parenchymal distortion) accompanying $\mathrm{MC}$ areas that could be detected as echogenic focus on USG were evaluated. The USG images of the patients were retrieved retrospectively from the PACS system and evaluated by a consensus of two radiologists ( $Y K$ and $\mathrm{NU}$ ) experienced in breast radiology.

\section{Biopsy Technique}

Sampling of mammographic MCs that could be detected by USG was performed under local anesthesia with a 14-gauge fully automatic core needle (Geotek, Ankara, Turkey). At least 5 samples were taken from each lesion. Whether the samples taken contained MC was evaluated with the X-ray of the specimen, and if it did not contain MC, the biopsy procedure was repeated. All biopsy procedures were performed under sterile conditions and the samples were sent to the pathology laboratory in sterile boxes.

\section{Histopathological Evaluation}

The histological type and grade of the samples (according to the Scarff-Bloom-Richardson grading system), estrogen receptor, progesterone receptor status and human epidermal growth factor receptor (HER)-2 positivity were examined.

\section{Statistical Analysis}

Data were evaluated numerically and as a percentage. Since the overall number of cases was relatively small, inferential statistical analysis was not performed.

\section{RESULTS}

Between June 2019 and January 2021, BI-RADS 4-5 MC were detected without accompanying mass in 50 of 9468 cases $(0.7 \%)$ who underwent mammography in our hospital, and MCs could be detected by USG in 43 (83\%) of these cases and core needle biopsy was performed under USG guidance. Seven patients with suspected MCs that were seen with mammography but could not be detected by USG were sent for excisional biopsy by mammography-guided wire marking (Figure 1). The mean 
age of the patients participating in the study was $45.27 \pm 8.58$ (3084). While 39 patients were detected by normal routine breast screening, 4 patients under the age of 40 with a family history applied with palpable stiffness. While mammographic breast density was type $C$ in $63 \%(n=27)$ of the patients, type $D$ in $23 \%$ $(n=10)$ and type $B$ in $14 \%(n=6)$, no patients were found in type $A$ category. $48.8 \%(n=21)$ of the calcifications were fine pleomorphic, $30 \%(n=13)$ amorphous, 16\% (7) coarse heterogeneous, 4.6\% (2) fine pleomorphic branching type. The mean mammographic MC area was $35.60 \pm 19.24 \mathrm{~mm}(7-90)$. While $70 \%(n=30)$ of the patients had asymmetrical density accompanying MCs on mammography, parenchymal distortion was found in $12 \%(n=5)$; on USG, hypoechoic area was found in $56 \%(n=24)$ of the patients, irregular ductal ectasia in $19 \%(n=8)$, parenchymal distortion in $9 \%(n=4)$ and microcyst cluster was the accompanying pathology in $10 \%$ $(n=4)$.

As a result of histopathological evaluation, benign pathology was found in $42 \%$ of patients $(n=18)$. In the benign group, 10 patients had non-proliferative fibrocystic change (NPFC) [fibrosis $(n=3)$, apocrine change $(n=1)$, mild ductal hyperplasia $(n=2)$, and $\operatorname{NPFC}(n=4)$ ]; 8 patients were diagnosed with PFC [usual ductal hyperplasia without atypia $(n=3)$, fluoride type hyperplasia without atypia $(n=1)$, columnar cell hyperplasia without atypia $(n=1)$, sclerosing adenosis $(n=2)$, and complex sclerosing lesion $(n=1)$ ]. An accompanying invasive component in the absolute pathology was detected in 10 patients who were diagnosed and marked with DCIS by core needle biopsy and referred for surgical operation. In total, $16 \%(n=7)$ of patients had DCIS [cribriform $(n=5)$, comedo $(n=2)$ ] and $42 \%$ of patients $(n=18)$ had malignant [invasive ductal carcinoma with in situ component (IDC+DCIS) $(n=10)$; pure IDC $(n=7)$; invasive lobular carcinoma $(n=1)]$ diagnosis. According to nuclear grading, 6 of DCIS were low grade (grade 1) and luminal A subtype, 1 was high grade (grade 2) and HER-2 (+). Rest of the malignant lesions were high grade grade 2-3) [8 luminal A, 3 luminal B, 7 HER-2 (+)] except one.

While the most common type of $\mathrm{MC}$ was fine pleomorphic in the benign group, the most common type of $M C$ was amorphous $M C$ in the PFC group and fine pleomorphic MC in the NPFC group. While the most common accompanying USG finding was a hypoechoic background in the malignant group $(n=17)$ and NPFC group $(n=6)$, the most common accompanying finding in the PFC group ( $n=3$ ) was ductal ectasia. In the malignant group, while ductal ectasia was observed in the DCIS group (pure DCIS and DCIS with IDC), it was a finding that was not observed in pure invasive cancers. While microcyst clusters were observed in the PFC group $(n=2)$ and DCIS group $(n=2)$, no microcyst clusters were found in the NPFC group and invasive ductal carcinoma group. The findings are summarized in Table 1. Case examples are shared in Figure 2-6.

\section{DISCUSSION}

Mammography is the most reliable imaging method used to detect and characterize MCs (13). BI-RADS was developed by the
American College of Radiology in order to use a common language by making a standardized assessment (16). As stated in the BlRADS mammography edition; skin and vascular calcifications, coarse or popcorn type, round, rim, dystrophic, tea-cut, suture calcifications are ate typically benign calcifications; amorphous, coarsely heterogeneous, fine pleomorphic and fine pleomorphic branching MCs are considered suspicious (17). In addition, the distribution of MCs is also important in terms of predicting malignancy; MCs with linear and segmental distribution are the riskiest distribution pattern in terms of malignancy $(13,16,18)$. Those with bilateral diffuse distribution are MCs that generally develop on the basis of fibrocystic disease $(4,16)$. The estimated value of BI-RADS for malignant MCs (BI-RADS 4-5) varies between $13 \%$ and $70 \%$ (16). Although stereotaxic biopsy is the most reliable method in the evaluation of suspicious patients, USG-guided biopsy is more advantageous compared to stereotaxic biopsy due to the above-mentioned features $(12,19)$. The disadvantage is that not all MCs without an accompanied mass can be detected by USG. While MCs in the 50-100 micron range can be observed on mammography, those in the 200-500 micron range can be observed on USG (20). Benign MCs that do not accompany the mass can usually be overlooked due to mottling artifact in the echogenic breast tissue, while malignant $\mathrm{MC}$ areas can be observed more easily with USG due to the hypoechoic pathological background $(10,12)$. In our study, we were able to detect $83 \%$ of suspicious and non-mass MCs with USG, and this rate is within the limits of the literature $(6,9,11,15,18,21)$. The malignancy risk of suspected MCs that can be detected by USG is higher than those detected only by mammography $(12,22,23)$. In our study, the majority of MCs detected by USG were malignant. In our study, the most common accompanying finding on USG in the malignant group was hypoechoic background, while in the benign group, the MC area was mostly observed on an isoechoic background. This finding is consistent with the literature (10). In USG, MCs can be seen as an echogenic focus alone, or they can be associated with irregular ductal ectasia with thickened walls, microcyst clusters, parenchymal distortion areas, heterogeneous hypoechoic areas or mass formation (10-12). These findings can be observed in both benign fibrocystic diseases and malignancy $(12,14)$. In our study, ductal ectasia and microcyst clusters are observed in PFCs, in DCIS with accompanying pure DCIS and invasive component, and they were not observed in the group with pure invasive cancer. The MCs that we could detect with USG were the MCs that clustered most frequently, followed by segmental and regional distribution. When the MC area was evaluated, except for two of the cases (7 $\mathrm{mm}$ and $8 \mathrm{~mm}$, both were invasive ductal carcinoma), the largest diameter of all was more than $1 \mathrm{~cm}$. While $62 \%$ of breasts with $\mathrm{MC}$ that can be observed by USG were category BI-RADS type " $\mathrm{C}$ ", no type "A" breasts were observed.

Fine pleomorphic type was the most commonly detected among MCs that could be observed by USG in both the malignant and benign groups, and the least common was the fine pleomorphic branching type. There are literature studies showing that the fine pleomorphic type is observed more frequently with USG 


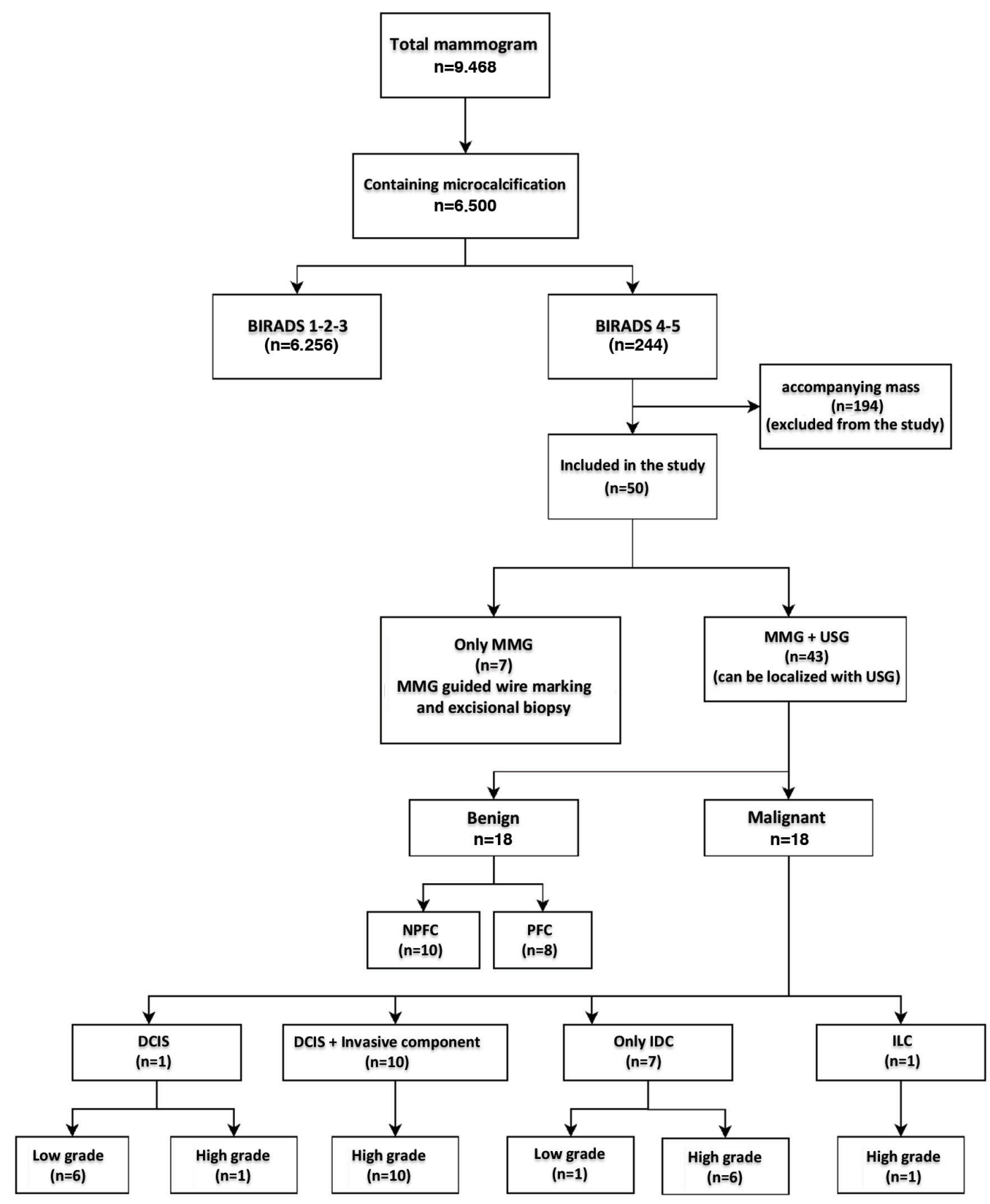

Figure 1. Algorithm for inclusion in the study

MMG: mammography, DCIS: ductal carcinoma in situ, NPFC: non-proliferative fibrocystic change, ILC: invasive lobular carcinoma, IDC: invasive ductal carcinoma, USG: ultrasonography, PFC: proliferative fibrocystic change, BI-RADS: Breast Imaging-Reporting and Data System

$(15,21,24)$. The low number of thin pleomorphic branching type can be explained by the exclusion of lesions accompanying the mass from the study. In the benign group, 8 had a cystic component and 6 had ductal ectasia. 6 of these patients had amorphous MC on mammography, 1 had coarse heterogeneous MC and 2 had fine pleomorphic MC. The majority of benign MCs without an accompanying cysts or dilated ducts were observed as echogenic spots on an isoechoic background, and the mammographic MC shape was amorphous and fine pleomorphic type.
The gold standard imaging method in the evaluation of MCs is mammography (5). The reason for investigating this area with USG is that the mass component, which is the marker of the possible invasive area, can be determined by USG and it allows biopsy to be performed from this solid area. Our study showed that USG is a useful method in the evaluation and biopsy of MCs without a mass. According to our results, we observed that hypoechoic background is a helpful finding in malign lesions and microcystic structures in lesions containing more in situ components, but it is not typical and can be observed in benign lesions as well. 


\begin{tabular}{|c|c|c|c|c|c|c|c|c|c|c|c|c|c|}
\hline & & $\begin{array}{l}\text { MMG } \\
\text { breast } \\
\text { density } \\
\text { BI-RADS }\end{array}$ & $\mathrm{n}$ & $\begin{array}{l}\text { MMG } \\
\text { MC } \\
\text { type }\end{array}$ & $\mathrm{n}$ & $\begin{array}{l}\text { MMG } \\
\text { distribution }\end{array}$ & $\mathrm{n}$ & $\begin{array}{l}\text { MMG } \\
\text { associated } \\
\text { findings }\end{array}$ & $\mathrm{n}$ & $\begin{array}{l}\text { MMG } \\
\text { category } \\
\text { BI-RADS }\end{array}$ & $\mathrm{n}$ & $\begin{array}{l}\text { Accompanying } \\
\text { findings on } \\
\text { USG }\end{array}$ & $\mathrm{n}$ \\
\hline \multirow[t]{7}{*}{ Benign (18) } & PFC (8) & Type B & 2 & $P$ & 3 & $\mathrm{R}$ & 5 & $A D$ & 5 & $4 \mathrm{~B}$ & 5 & $\mathrm{DE}$ & 3 \\
\hline & & Type C & 5 & $A$ & 4 & C & 2 & D & 2 & $4 \mathrm{~A}$ & 3 & Нypo & 2 \\
\hline & & Type D & 1 & $\mathrm{CH}$ & 1 & $S$ & 1 & - & 1 & - & - & $\mathrm{CM}$ & 2 \\
\hline & & - & - & & - & - & - & - & - & - & - & Dis & 1 \\
\hline & NPFC (10) & Type B & 1 & $P$ & 5 & C & 7 & $A D$ & 5 & $4 \mathrm{~B}$ & 5 & $\mathrm{DE}$ & 2 \\
\hline & & Type C & 6 & A & 4 & $\mathrm{R}$ & 3 & D & 1 & $4 \mathrm{~A}$ & 5 & Dis & 2 \\
\hline & & Type D & 3 & $\mathrm{CH}$ & 1 & - & - & - & 2 & - & - & Нypo & 6 \\
\hline \multirow[t]{5}{*}{ DCIS (7) } & Cribriform type (5) & Type B & 1 & FP & 3 & C & 3 & $A D$ & 4 & $4 C$ & 3 & Нyро & 3 \\
\hline & & Type C & 3 & A & 2 & $\mathrm{~S}$ & 1 & D & 1 & $4 \mathrm{~B}$ & 2 & $\mathrm{CM}$ & 1 \\
\hline & & Type D & 1 & FP & 1 & $\mathrm{R}$ & 1 & - & - & - & - & DE & 1 \\
\hline & Comedo type (2) & Type C & 2 & FP & 1 & $\mathrm{~S}$ & 2 & $A D$ & 2 & 5 & 2 & Нypo & 1 \\
\hline & & - & - & FPB & 1 & - & - & - & - & - & - & $\mathrm{CM}$ & 1 \\
\hline \multirow[t]{8}{*}{ Invasive (18) } & IDC+DCIS (10) & Type B & 1 & FP & 6 & $\mathrm{R}$ & 5 & $A D$ & 7 & $4 \mathrm{~B}$ & 4 & $\mathrm{DE}$ & 2 \\
\hline & & Type C & 6 & A & 1 & C & 3 & - & 3 & $4 C$ & 3 & Нypo & 5 \\
\hline & & Type D & 3 & $\mathrm{CH}$ & 2 & $\mathrm{~S}$ & 2 & - & - & 5 & 3 & Dis & 1 \\
\hline & & - & - & FPB & 1 & - & - & - & - & - & - & - & - \\
\hline & IDC (7) & Type B & 1 & FP & 3 & C & 4 & $A D$ & 5 & $4 \mathrm{~B}$ & 3 & Нyро & 7 \\
\hline & & Type C & 5 & $\mathrm{CH}$ & 3 & $S$ & 2 & D & 1 & 5 & 2 & - & - \\
\hline & & Type D & 1 & A & 1 & $\mathrm{R}$ & 1 & $A D$ & 1 & - & - & - & - \\
\hline & ILC (1) & Type D & 1 & FP & 1 & $\mathrm{R}$ & 1 & $A D$ & 1 & 5 & 1 & Hypo & 1 \\
\hline
\end{tabular}

A: amorphous, AD: asymmetric density, C: clustering, $\mathrm{CH}$ : coarse heterogeneous, $\mathrm{CM}$ : clustered microcysts, Dis: distortion, DCIS: ductal carcinoma in situ, DE: ductal ectasia, FP: fine pleomorphic, FPB: fine pleomorphic branching, Hypo: hypoechogenicity, IDC: invasive ductal carcinoma, ILC: invasive lobular carcinoma, MC: microcalcification, MMG: mammography, NPFC: non-proliferative fibrocystic change, P: pleomorphic, PFC: proliferative fibrocystic change, R: regional, S: segmental, USG: ultrasonography

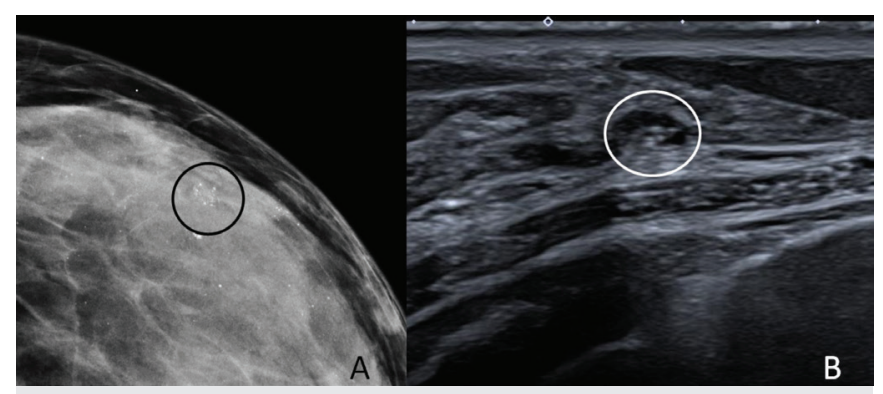

Figure 2. Example of mild epithelial hyperplasia: Asymptomatic 43-year-old woman, clustered amorphous microcalcifications in the outer part of the left breast were observed on screening mammography (A), and echogenic foci on a microcystic background were observed on ultrasonography (B)

Prospective studies with larger number of patients are needed to reveal the importance of these accompanying findings in the prediction of malignancy and invasiveness.

\section{Study Limitations}

The most important limitation of our study is the small number of patients. Another limitation of ours is the lack of long-term followup of patients who had benign results with core biopsy. In our

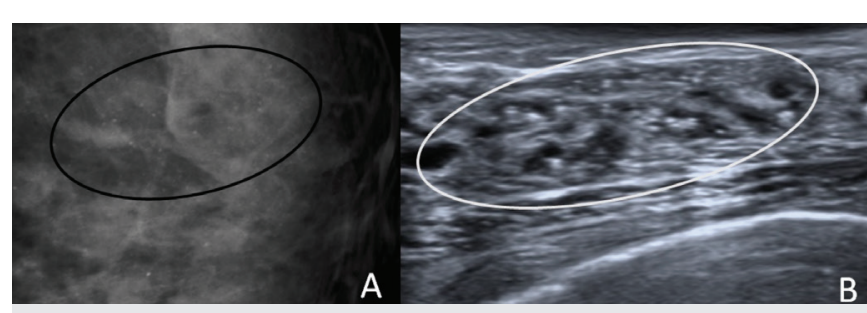

Figure 3. Example of proliferative type fibrocystic change: A 42-year-old asymptomatic woman, regional amorphous microcalcifications in the retroareolar area were observed on screening mammography (A), and echogenic foci and accompanying dilated ductal enlargements on a microcystic background were observed on ultrasonography (B)

study, MCs occupying less than $0.7 \mathrm{~cm}$ could not be evaluated because they could not be observed by USG. In addition, another limitation of our study is that USG is operator dependent and researchers may have dissensus.

\section{CONCLUSION}

Although USG is a limited imaging method in the evaluation of MCs, it is a technique that can help radiologists to increase the specificity of mammography especially in the evaluation 

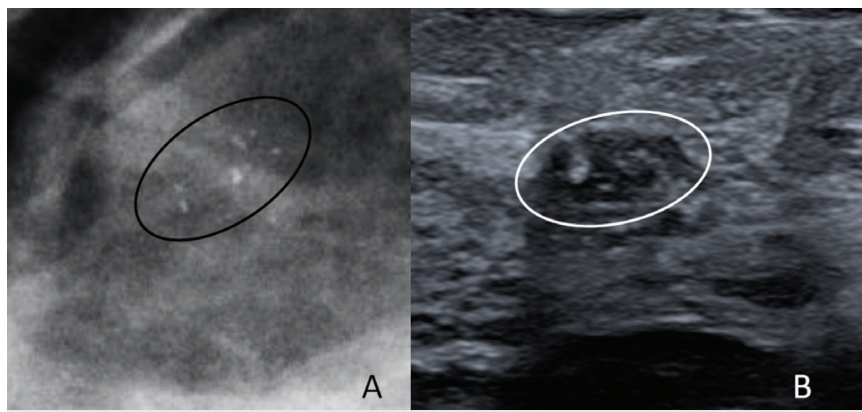

Figure 4. Example of high-grade ductal carcinoma in situ: A 38-year-old female patient, previously diagnosed with invasive ductal carcinoma of the left breast, had clustered fine pleomorphic microcalcifications in her right breast (A), and echogenic spots on a hypoechoic background on ultrasonography (B)

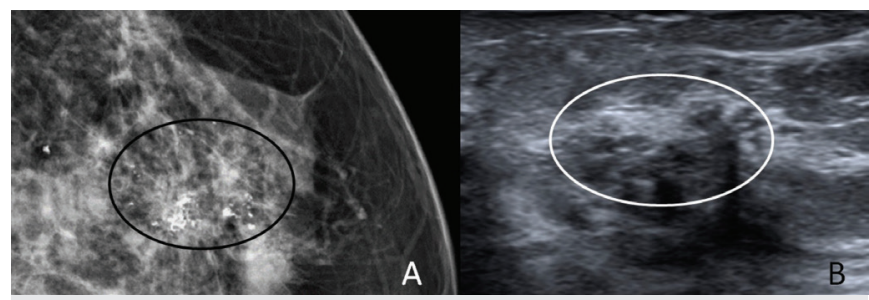

Figure 5. Example of invasive carcinoma accompanying ductal carcinoma in situ: In the mammography of a 45-year-old woman for screening, finely branching microcalcifications showing a regional distribution in the upper part of the right breast was observed (A); accompanying microcystic structures on a hypoechoic background and slightly dilated ducts were observed on ultrasonography (B)

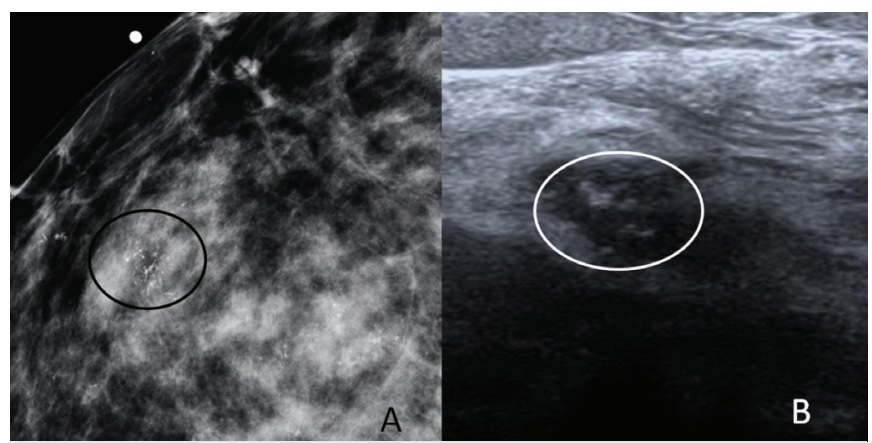

Figure 6. Example of invasive ductal carcinoma: In the mammography of a 43-year-old female patient taken before breast reduction surgery, thin pleomorphic branching type microcalcifications with focal distribution in the upper part of the right breast were observed (A) and echogenic foci on a hypoechoic background were observed on ultrasonography (B)

of $\mathrm{MC}$ clusters larger than $1 \mathrm{~cm}$, determine the indication and priority of biopsy, and guide the biopsy procedure.

Ethics Committee Approval: This retrospective study was conducted following Gaziosmanpaşa Training and Research Hospital Ethics Committee approval (approval number: 252, approval date: 14/04/2021).

Informed Consent: Informed consents was obtained in order to use the recorded data of the patients.
Peer-review: Externally peer-reviewed.

Author Contributions: Surgical and Medical Practices - E.Y., A.N.Ş.; Concept - Y.K., N.U.; Design - Y.K.; Data Collection and/or Processing Y.K., N.U.; Analysis and/or Interpretation - Y.K., D.E.T.Ş.; Literature Search - D.E.T.Ş.; Writing - Y.K., D.E.T.Ş.

Conflict of Interest: The authors have no conflict of interest to declare.

Financial Disclosure: The authors declared that this study has received no financial support.

\section{REFERENCES}

1. Dershaw DD, Abramson A, Kinne DW. Ductal carcinoma in situ: mammographic findings and clinical implications. Radiology 1989; 170 : 411-5.

2. Schnitt SJ, Silen W, Sadowsky NL, Connolly JL, Harris JR. Ductal carcinoma in situ (intraductal carcinoma) of the breast. $\mathrm{N}$ Engl J Med 1988; 318: 898-903.

3. Stomper PC, Connolly JL, Meyer JE, Harris JR. Clinically occult ductal carcinoma in situ detected with mammography: analysis of 100 cases with radiologic-pathologic correlation. Radiology 1989; 172: 235-41.

4. Bent CK, Bassett LW, D'Orsi CJ, Sayre JW. The Positive predictive value of bı-rads microcalcification descriptors and final assessment categories. Am J Roentgenol 2010; 194: 1378-83.

5. Craft M, Bicknell AM, Hazan GJ, Flegg KM. Microcalcifications detected as an abnormality on screening mammography: outcomes and followup over a five-year period. Int J Breast Cancer 2013; 2013: 458540.

6. Liu J, Huang L. Image-guided vacuum-assisted breast biopsy in the diagnosis of breast microcalcifications. J Int Med Res 2018; 46: 2743-53.

7. Peng Y, Luo Z, Ni J, Cui H, Lu B, Xiang A, et al. Precision biopsy of breast microcalcifications: An improvement in surgical excision. Oncol Lett 2018 May 22 [cited 2020 Dec 21]; doi: 10.3892/ol.2018.8787

8. Gokhale S. Ultrasound characterization of breast masses. Indian J Radiol Imaging 2009; 19: 242-7.

9. Machado P, Eisenbrey JR, Stanczak M, Cavanaugh BC, Zorn LM, Forsberg F. Characterization of breast microcalcifications using a new ultrasound Image-processing technique. J Ultrasound Med 2019; 38: 1733-8.

10. Moon WK, Im JG, Koh YH, Noh DY, Park IA. US of Mammographically Detected Clustered Microcalcifications. Radiology. 2000; 217: 849-54.

11. Relea A, Alonso JA, González M, Zornoza C, Bahamonde S, Viñuela BE, et al. Usefulness of the twinkling artifact on Doppler ultrasound for the detection of breast microcalcifications. Radiologia (Engl Ed) 2018; 60: 413-23.

12. Soo MS, Baker JA, Rosen EL. Sonographic detection and sonographically guided biopsy of breast microcalcifications. Am J Roentgenol 2003; 180: 941-8.

13. Wilkinson $L$, Thomas $V$, Sharma N. Microcalcification on mammography: approaches to interpretation and biopsy. Br J Radiol. 2016; 90: 20160594.

14. Soo MS, Baker JA, Rosen EL, Vo TT. Sonographically guided biopsy of suspicious microcalcifications of the breast: a pilot study. Am J Roentgenol2002; 178: 1007-15.

15. Yang WT, Suen M, Ahuja A, Metreweli C. In vivo demonstration of microcalcification in breast cancer using high resolution ultrasound. $\mathrm{Br} \mathrm{J}$ Radiol 1997; 70: 685-90.

16. Sickles EA, D'Orsi CJ, Bassett LW, Appleton CM, Berg WA, Burnside ES. ACR BI-RADS ${ }^{\circledR}$ Atlas, Breast imaging reporting and data system. Reston, VA: American College of Radiology. 2013; 39-48.

17. Nalawade YV. Evaluation of breast calcifications. Indian J Radiol Imaging 2009; 19: 282-6.

18. Hadi Q, Masroor I, Hussain Z. Mammographic criteria for determining the diagnostic accuracy of microcalcifications in the detection of malignant breast lesions. Cureus 2019; 11: e5919.

19. Liberman L. Percutaneous imaging-guided core breast biopsy: state of the art at the millennium. Am J Roentgenol 2000; 174: 1191-9.

20. Wang LC, Sullivan M, Du H, Feldman MI, Mendelson EB. US Appearance of Ductal Carcinoma in Situ. Radiographics 2013; 33: 213-28.

21. Duran Özel B, Özel D, Özkan F, Halefoğlu AM, Özer Ö, Başak M. Can we determine biopsy indication by using BI-RADS ultrasonography findings for solid breast masses. S..E.E.A.H. Tıp Bülteni 2015; 49: 284-8. 
22. Bitencourt AGV, Graziano L, Guatelli CS, Albuquerque MLL, Marques EF. Ultrasound-guided biopsy of breast calcifications using a new image processing technique: initial experience. Radiol Bras 2018; 51: 106-8.

23. Teh WL, Wilson ARM, Evans AJ, Burrell H, Pinder SE, Ellis IO. Ultrasound guided core biopsy of suspicious mammographic calcifications using high frequency and power Doppler ultrasound. Clin Radiol 2000; 55: 390-
24. Pan S, Liu W, Jin K, Liu Y, Zhou Y. Ultrasound-guided vacuum-assisted breast biopsy using Mammotome biopsy system for detection of breast cancer: results from two high volume hospitals. Int J Clin Exp Med 2014; 7: 239-46. 